\title{
Da Amazônia ao guia: os dilemas entre a alimentação quilombola e as recomendações do guia alimentar para a população brasileira
} From the Amazon to the guidelines: the dilemmas between quilombola foods and the recommendations of the dietary guidelines for the Brazilian population

Nádia Alinne Corrêa ${ }^{a}$

(D) https://orcid.org/0000-0002-7833-3919

E-mail: nadiaalinneføgmail.com

Hilton P. Silva ${ }^{a}$

(D) https://orcid.org/0000-0002-3287-3522

E-mail: hdasilva®ufpa.br

anniversidade Federal do Pará. Instituto de Filosofia e Ciências Humanas. Programa de Pós-Graduação em Antropologia. Belém, PA, Brasil.

\section{Correspondência}

Nádia Alinne Corrêa

Instituto de Filosofia e Ciências Humanas. Cidade Universitária Professor José da Silveira Netto. Av. Perimetral, s/n. Belém, PA, Brasil. CEP 66075-110.

\section{Resumo}

O objetivo deste trabalho é analisar se o hábito alimentar das famílias quilombolas paraenses segue as orientações do Guia Alimentar para a População Brasileira, publicado pelo Ministério da Saúde, em 2014. Foram realizadas entrevistas semiestruturadas nas comunidades de Santo Antônio (Concórdia do Pará, nordeste paraense) e São João (Salvaterra, ilha do Marajó) sob o protocolo CEP o6o/o7. Foram feitas análises do consumo e das preferências alimentares de acordo com o guia. Os resultados evidenciam: alto consumo de café adoçado, feijão, arroz e farinha; baixa participação de verduras, legumes e frutas na dieta dos entrevistados. Alimentos como pão, leite de vaca, macarrão, margarina e bolacha salgada são as formas comuns de diversificar os alimentos consumidos pelo grupo. Como fontes proteicas, destacam-se a carne vermelha - silvestre ou não -, o pescado, o charque, o frango e o ovo de galinha. São apresentadas algumas contradições do guia quando aplicado às comunidades. Apesar dos avanços do guia, conclui-se que o cumprimento das orientações para uma alimentação adequada e saudável nos grupos quilombolas da região amazônica enfrenta desafios. Guias alimentares são importantes para a saúde e a nutrição da população, porém precisam ser combinados com outros tipos de intervenções que respeitem a diversidade cultural do país.

Palavras-chave: Grupo com Ancestrais do Continente Africano; Saúde da População Negra; Cultura Alimentar; Dieta; Guias Alimentares. 
The objective of this study is to analyze the food habit of quilombola families in Pará, following the guidelines of the Food Guide for the Brazilian Population published by the Brazilian Health Ministry in 2014. Semi-structured interviews were conducted in the communities of Santo Antônio (Concórdia do Pará, in the Northeast) and São João (Salvaterra, on Marajó Island) under protocol CEP 060/07. Analysis of consumption and preferences were made according to the guide. The results show a high consumption of sweetened coffee, beans, rice and flour, and a low participation of vegetables and fruits in the interviewees' diet. Foods such as bread, cow's milk, pasta, margarine, and salt crackers are common means to diversify the foods consumed by the group. As protein sources, the most notable were red meat - wild or not -, fish, beef jerky, chicken and chicken eggs. Some contradictions of the Guide are discussed in relation to such communities. Despite the advancements promoted by the guide, we conclude that following the guidelines for an adequate and healthy food habit in quilombola groups in the Amazon region presents many challenges. Food guides are important for the health and nutrition of the population; however, they need to be combined with other types of interventions that respect the country's cultural diversity.

Keywords: Group with Ancestors from the African Continent; Health of the Black Population; Food Culture; Diet; Food Guides.
Desde a Second International Conference on Nutrition (WHO; FAO, 2014), o eixo comum das ações globais dos Estados-membros tem sido o compromisso de orientar as pessoas a escolherem alimentos saudáveis para, com isso, eliminar todas as formas de desnutrição. Encorajados pela Organização das Nações Unidas para a Alimentação e a Agricultura e pela Organização Mundial da Saúde, todos os países devem instituir políticas de nutrição que levem à população informações que promovam uma alimentação diversificada e equilibrada em todas as fases da vida (WHO; FAO, 2014).

O Plano Mundial de Ação para a Nutrição (WHO, 2017) incluiu a promoção de dietas saudáveis a partir do desenvolvimento de guias alimentares para diferentes grupos etários das populações de cada país; o objetivo dos guias alimentares seria fornecer aconselhamento nutricional para a melhoria da qualidade de vida da população, além de orientar as políticas nacionais de alimentação e a indústria de alimentos.

No Brasil, as diretrizes dietéticas foram revisadas e o Guia Alimentar para a População Brasileira (GAPB) mudou de foco. $\mathrm{O}$ incentivo aos brasileiros passou a concentrar-se em orientações para uma alimentação adequada e saudável com base no consumo de alimentos variados, regionais, sócio e ambientalmente sustentáveis, ressaltando-se a importância da autonomia das escolhas em detrimento da preocupação com a taxa de nutrientes (Andrade; Bocca, 2016; Brasil, 2014).

A implantação do GAPB, no entanto, enfrenta muitos obstáculos, visto que o comportamento alimentar é múltiplo e diversificado, variando de acordo com os diferentes grupos populacionais, a sazonalidade dos recursos naturais e as condições socioeconômicas dos consumidores (Silva; Begossi, 2009). A preocupação com os direitos dos quilombolas, concebidos como grupos étnicos, insere-se nesse contexto.

As comunidades tradicionais, em que se encaixam os quilombolas, são organizações sociais que vivem de formas produtivas ancoradas na autossubsistência, com pouca ou nenhuma acumulação de capital (Brandão; Jorge, 2013). 
Por essa razão, são vulneráveis aos modelos de desenvolvimento econômico que registram altos índices de degradação ambiental e crescimento populacional desigual - marcados por conflitos, como é o caso do ambiente amazônico.

Apesar dos milhares de quilômetros de floresta - com mais de 1,5 milhões de espécies vegetais catalogadas, a melhor oferta de alimentos naturais, água e uma rica diversidade faunística -, os descendentes da população escravizada são os que mais sofrem de insegurança alimentar e nutricional (Guimarães; Silva, 2015; Silva et al., 2008).

Quando se fala de comunidades quilombolas, cabe sublinhar que essas são redutos de sobrevivência e de resistência, reconhecidas oficialmente como grupos que apresentam presunção de ancestralidade negra, com trajetórias históricas próprias e relações socioterritoriais específicas (Brasil, 2003). Os quilombos são, porém, invisibilizados e estão colocados em situação de vulnerabilidade por causa do racismo estrutural e de conflitos socioterritoriais com os interesses do agronegócio, da mineração, do hidronegócio, de madeireiros e de fazendeiros.

Uma pesquisa do Ministério do Desenvolvimento Social e Combate à Fome sobre segurança alimentar e nutricional de crianças menores de 5 anos, realizada no período de 1995 a 2009, em 9.191 domicílios quilombolas em territórios titulados, constatou que, na região do baixo Amazonas, a cada cinco residências, quatro apresentaram crianças que ficaram sem comer por não possuir comida em casa - o que corresponde a 79,1\% do total; no nordeste paraense, o percentual foi de 43,0\% (Pinto et al., 2014). Em contrapartida, os quadros de sobrepeso e de obesidade apresentaram forte ligação com as residências em que o cardápio quilombola, associado à condição de baixa renda, continha alimentos com alto valor energético e baixo valor nutricional, conhecidos como ultraprocessados (Pinto et al., 2014).

O impacto desse novo padrão dietético - tanto na saúde quanto no bem-estar - caracteriza um processo de transição alimentar e tem levantado diversos debates sobre os fatores bioantropológicos, sociais e econômicos que intervêm no processo de saúde e nutrição em grupos rurais no Brasil (Borges, 2011; Silva, 2009, 2011; Silva; Filgueiras, 2019). O reconhecimento desse padrão emergente explica por que líderes mundiais decidiram trabalhar juntos para erradicar todas as formas de má nutrição até 2030, adotando metas para os Objetivos de Desenvolvimento Sustentável e proclamando o período de 2016 a 2025 como a Década da Nutrição (WHO, 2017).

O maior desafio da saúde pública nos tempos contemporâneos é a má nutrição resultante de uma alimentação inadequada, seja em quantidade, seja em qualidade, manifestando-se em desnutrição, deficiência de nutrientes e doenças crônicas não transmissíveis (Boatemaa; Drimie; Pereira, 2018). Considerando as especificidades étnico-culturais dos grupos quilombolas, torna-se ainda mais desafiador examinar as dimensões do "que", "quando", "como" e "com quem" como categorias de análise do ato de comer, propostas pelo GAPB, uma vez que estes se encontram em situação de extrema pobreza, precário acesso às políticas públicas e falta de espaço para o cultivo de alimentos, decorrentes do racismo estrutural (Corrêa; Cardoso; Silva, 2020; Cavalcante; Silva, 2019).

Esse conjunto de perspectivas, especialmente no que concerne ao consumo alimentar de grupos quilombolas na Amazônia, está no centro desta análise. O objetivo foi investigar de que forma o consumo alimentar das famílias de duas diferentes comunidades quilombolas no estado do Pará, na região Norte do Brasil, dialoga com as orientações do GAPB. Parte-se da observação que ainda falta no país uma compreensão maior do universo alimentar dos grupos quilombolas, bem como instrumentos oficiais que definam orientações para escolhas alimentares e hábitos saudáveis direcionados a grupos específicos.

\section{Área do estudo}

\section{Entre os quilombos}

O estado do Pará está entre os quatros estados da federação com o maior número de grupos populacionais autodeclarados quilombolas: são aproximadamente 523 comunidades reconhecidas e certificadas (Gomes, 2015). De forma geral, elas estão localizadas em ambientes com condições precárias de saneamento, sem acesso à educação e aos serviços de saúde, com baixo fornecimento de água potável e em risco alimentar e nutricional (Araújo et al., 2019; Melo; Silva, 2015). 
O quilombo Santo Antônio, dentro desse contexto sociopolítico, localiza-se no município de Concórdia do Pará/PA, na região geográfica imediata de Belém, na comunidade PA-140, ramal do km 39 . 0 município possui 28.216 habitantes, dos quais $45,99 \%$ vivem em situação de pobreza. 0 Índice de Desenvolvimento Humano (IDH) é baixo (o,566), refletido na alta mortalidade infantil e analfabetismo $-15^{\circ}$ e $64^{\circ}$ lugar no ranking estadual, respectivamente (IBGE, 2010).

A construção do território étnico tem como protagonista a Associação das Comunidades Remanescentes de Quilombo Nova Esperança de Concórdia do Pará, fundada em 2001. Em conjunto com outras cinco comunidades, os quilombolas de Santo Antônio reivindicam a regularização da terra na categoria coletiva ante a expansão do agronegócio de dendê na região.

A garantia dos alimentos advém da pesca artesanal, da caça e da criação de animais de pequeno porte. Outra prática cotidiana das famílias de Santo Antônio é a horticultura. Para complementar a renda familiar e ter acesso a alimentos básicos, os moradores da comunidade têm desenvolvido o extrativismo de cipós para a confecção de peneiras e abanos de uso doméstico e para venda, e de sementes para a confecção de colares e adornos. Como forma de dinamizar a economia doméstica, as famílias atendem o programa de alimentação escolar por meio do fornecimento de produtos locais.

O quilombo São João tem localização distinta. Situado na região geográfica imediata de SoureSalvaterra, é parte integrante da comunidade quilombola Mangueiras, no município de Salvaterra, na ilha do Marajó/PA. Esse município possui 20.183 habitantes, com um IDH mediano (o,6o8), atingindo o $12^{\circ}$ lugar no ranking estadual da mortalidade infantil e o $125^{\circ}$ de analfabetismo. Mais da metade de sua população $(50,16 \%)$ vive em situação de pobreza (IBGE, 2010). O território quilombola de Salvaterra é formado por 17 comunidades que, desde 2007, reivindicam a titulação de suas terras ante a expansão das indústrias do turismo e dos cosméticos (Gomes; Schmitz; Bringel, 2018).

$\mathrm{Na}$ comunidade, os meios de subsistência são a pesca e os recursos recebidos dos programas assistenciais, como o Bolsa-Família. A área destinada à agricultura é reduzida devido à expansão do agronegócio. A situação da saúde caracteriza-se pelo aumento do sobrepeso ou obesidade. Um estudo com adultos e idosos da região revelaram que 58,14\% $(n=108)$ dos participantes encontravam-se nesse quadro (Almeida et al., 2016).

\section{Método}

Para atender o objetivo da pesquisa, o estudo contou com a participação de 60 chefes de família atendidos no serviço ambulatorial nas duas comunidades, Santo Antônio e São João, durante 2009 e 2010. Em cada localidade, foram promovidos encontros com a equipe durante a ação do amplo projeto Corpo presente: representações de saúde entre quilombolas e políticas públicas, aprovado pelo CEP-ICS-UFPA sob $\mathrm{n}^{0}$ 060/07.

A realização das entrevistas sobre o consumo alimentar foi norteada pelo modelo de recordatório de 24 horas adaptado como entrevista semiestruturada. Os chefes de família informaram os alimentos consumidos nas refeições ao longo do dia anterior e sua justificativa para o consumo. Para compreender as preferências alimentares, foram adicionadas informações por meio das perguntas: o que você mais gosta de comer? Quando é que você come esses alimentos? Todas as informações obtidas compuseram um banco de dados no programa Microsoft Excel, posteriormente exportados para o Programa Statistical Package for the Social Sciences (SPSS), versão 15.o, para a análise dos dados.

A análise foi realizada com base em oito grupos de alimentos mencionados no GAPB. Esses grupos correspondem ao conjunto de alimentos que possuem uso culinário e perfil nutricional semelhantes: carnes e ovos, cereais, feijões, frutas, legumes e verduras, leites e queijos, raízes e tubérculos, óleos e gorduras. As informações coletadas também foram analisadas sob a ótica dos princípios do Guia Alimentar no que diz respeito ao tipo de processamento dos alimentos, conforme as categorias in natura ou minimamente processados, óleo, gordura, sal e açúcar, alimentos processados e alimentos ultraprocessados.

Como limitações do método, tem-se que não foi possível mensurar as quantidades de alimentos ingeridos pelas famílias, o consumo de alimentos do calendário festivo ou ritualístico das comunidades 
ou a frequência dos alimentos ao longo do dia, da semana ou do mês, apenas seu tipo.

\section{Resultados e discussão}

\section{A diversidade alimentar das famílias de Santo Antônio e São João}

O consumo alimentar das comunidades quilombolas de Santo Antônio e São João caracteriza-se pelo alto índice de tubérculos e cereais - em contraposição às frutas e verduras. Dos 63 produtos mencionados pelos participantes, o café adoçado, o trinômio arroz-feijãofarinha e a carne vermelha foram os mais citados por grande parte das famílias.

Considerando o contexto rural no qual foram identificados, esses alimentos definem as refeições principais - desjejum, almoço e jantar - como fontes promotoras de energia humana. Murrieta (2001), ao analisar as escolhas alimentares dos habitantes da ilha de Ituqui, no Pará, destacou que o hábito matinal do consumo de café e de uma porção concentrada de açúcar é fundamental como fonte de energia durante o trabalho no campo. Para ele, a combinação de açúcar e cafeína poderia manter as pessoas por horas com pouca ou nenhuma comida sólida durante as manhãs, uma vez que a primeira refeição significativa do dia ocorreria por volta do meio-dia.

0 trinômio arroz-feijão-farinha, designado pelos termos "comida de verdade", "rancho" e "boia”, caracteriza as refeições fortes consideradas capazes de matar a fome. Cascudo (2011), ao descrever a história da alimentação no Brasil mencionou o binômio feijão-farinha como uma combinação de suma importância para sustentar o corpo - alimentos esses que, juntos, governam o cardápio brasileiro desde a primeira metade do século XVII.

Ademais, o hábito de comer arroz com feijão é popular, mas não indispensável. Na Amazônia, pode-se observar que, nas comunidades tradicionais, a farinha está presente no cardápio cotidiano para complementar a refeição junto com a caça ou a pesca, ou mesmo em substituição ao arroz-e-feijão em períodos de escassez. De acordo com a Tabela 1, o consumo do café adoçado fez parte de $98,3 \%$ das refeições matinais, e o feijão $(73,3 \%)$, o arroz $(71,7 \%)$ e a farinha $(68,3 \%)$ estavam fortemente presentes nas dietas quilombola analisadas. Outros alimentos, como o pão $(63,3 \%)$ com ou sem margarina (31,7\%), o leite de vaca $(58,3 \%)$, o macarrão $(36,7 \%)$ e a bolacha salgada (cream cracker) $(26,7 \%)$, foram as formas mais evidenciadas de diversificar os alimentos consumidos pelo grupo.

Tabela I - Frequência e percentuais do consumo de alimentos nas famílias dos quilombos São João e Santo Antônio, Pará, Brasil, 2009 ( $n=60)$

\begin{tabular}{|c|c|c|c|c|c|}
\hline Alimentos & $n$ & $\%$ & Alimentos & $n$ & $\%$ \\
\hline \multicolumn{6}{|c|}{ Alimentos in natura / Minimamente processados / Processados } \\
\hline Carnes e ovos & & & Legumes e verduras & & \\
\hline Bucho, vísceras & 2 & 3,3 & Alface & 4 & 6,7 \\
\hline Camarão & 1 & 1,7 & Alho & 6 & 10,0 \\
\hline Carne & 32 & 53,3 & Canela, chá & 1 & 1,7 \\
\hline Frango & 14 & 23,3 & Cariru & 5 & 8,3 \\
\hline Mocotó & 1 & 1,7 & Cebola & 12 & 20,0 \\
\hline Ovo de galinha & II & 18,3 & Chicória & 2 & 3,3 \\
\hline Peixe & 28 & 46,7 & Coentro (cheiro-verde) & 3 & 5,0 \\
\hline Cereais & & & Colorau & 3 & 5,0 \\
\hline Arroz & 43 & 71,7 & Cominho & 1 & 1,7 \\
\hline Bolo & । & $\mathrm{I}, 7$ & Couve & 5 & 8,3 \\
\hline
\end{tabular}


Tabela I - Continuação

\begin{tabular}{|c|c|c|c|c|c|}
\hline Alimentos & n & $\%$ & Alimentos & $n$ & $\%$ \\
\hline \multicolumn{6}{|c|}{ Alimentos in natura / Minimamente processados / Processados } \\
\hline Fubá & 7 & $\mathrm{II}, 7$ & Maxixe & 8 & 13,3 \\
\hline Macarrão & 22 & 36,7 & Pepino & 4 & 6,7 \\
\hline Pão & 38 & 63,3 & Pimentinha & I & ।,7 \\
\hline Rosca & 4 & 6,7 & Tomate & 6 & 10,0 \\
\hline Torrada & 2 & 3,3 & \multicolumn{3}{|l|}{ Leites e queijos } \\
\hline Feijões & & & Leite de búfala & 5 & 8,3 \\
\hline Feijão & 44 & 73,3 & Leite de coco & I & ।,7 \\
\hline Frutas & & & Leite de vaca & 35 & 58,3 \\
\hline Abacaxi & 1 & $\mathrm{I}, 7$ & \multicolumn{3}{|l|}{ Raízes e tubérculos } \\
\hline Açaí & 7 & 11,7 & Batata & 13 & 21,7 \\
\hline Banana & 3 & 5,0 & Cenoura & 10 & 16,7 \\
\hline Café & 59 & 98,3 & Farinha, mandioca & 41 & 68,3 \\
\hline Cupuaçu & 1 & $\mathrm{I}, 7$ & Farinha, tapioca & 3 & 5,0 \\
\hline Laranja & 4 & 6,7 & \multicolumn{3}{|l|}{ óleos e gorduras } \\
\hline Manga & 3 & 5,0 & Açúcar & 60 & 100,0 \\
\hline Maracujá & 1 & $\mathrm{I}, 7$ & óleo de soja & 60 & 100,0 \\
\hline Melancia & 1 & 1,7 & Sal & 60 & 100,0 \\
\hline \multicolumn{6}{|c|}{ Alimentos ultraprocessados } \\
\hline Achocolatado & 6 & 10,0 & Massa, sopa & 4 & 6,7 \\
\hline Bolacha & 16 & 26,7 & Massa, mingau & 7 & 11,7 \\
\hline Charque & 19 & 31,7 & Mortadela & 4 & 6,7 \\
\hline Conserva & 2 & 3,3 & Refrigerante & 2 & 3,3 \\
\hline Goiabada & 1 & $\mathrm{I}, 7$ & Sardinha & 1 & 1,7 \\
\hline Macarrão instantâneo & 1 & $\mathrm{I}, 7$ & Suco artificial & 6 & 10,0 \\
\hline Margarina & 19 & $3 \mathrm{I}, 7$ & Tempero completo & 2 & 3,3 \\
\hline
\end{tabular}

Com base nesses dados, é pertinente ressaltar que a quebra da monotonia alimentar tem a ver com as condições econômicas das famílias. Alguns estudos têm considerado que as escolhas individuais das populações tradicionais dependem de fatores como a renda extra trazida pelo Programa Bolsa Família e outros, por exemplo (Ivanova, 2010; Murrieta, 1998; Silva; Garavello, 2012).
Nascimento e Guerra (2016), ao analisarem as práticas alimentares da comunidade quilombola do Baixo Acari, em Abaetetuba/PA, observaram que a carência de renda foi recorrente na fala de $80 \%$ dos entrevistados. Para eles, a dificuldade de obtenção de renda influenciava substancialmente a qualidade dos alimentos consumidos. Na percepção dos sujeitos, na ausência do dinheiro, "tinham que 
dar o jeito" - o que significava recorrer ao mingau de farinha ou de açaí, ao peixe, ao camarão e ao açaí in natura.

Achados próximos sobre outros elementos nutricionais podem ser observados nas duas comunidades do presente estudo. As fontes proteicas estavam em torno da carne vermelha (53,3\%) e do pescado (46,7\%); outras opções citadas foram o charque $(31,7 \%)$, o frango $(23,6 \%)$ e o ovo de galinha (18,3\%). A carne foi, em parte, proveniente de animais silvestres.

Entre as espécies de caça citadas estão o tatu, o veado e a paca. Em relação à pesca local, mesmo com grandes dificuldades de acesso às águas do rio devido aos conflitos com fazendeiros, foi possível registrar o consumo de oito espécies de peixes da região (Quadro 1).

Quadro I - Alimentos tradicionais consumidos pelas famílias dos quilombos São João e Santo Antônio, Pará, Brasil, 2009

\begin{tabular}{|c|c|}
\hline $\begin{array}{l}\text { Alimentos } \\
\text { tradicionais }\end{array}$ & Nome científico \\
\hline \multicolumn{2}{|l|}{ Caça } \\
\hline Paca & Cuniculus paca \\
\hline Tatu & Priodontes $s p$ \\
\hline Suaçu (veado) & Mazama sp \\
\hline \multicolumn{2}{|l|}{ Peixes } \\
\hline Acará & Pterophyllum scalare \\
\hline Anujá & Trachycorystes galeatus \\
\hline Aracu, piaba & Leporinus obtusidens \\
\hline Bagre & Hexanematichthys grandoculis \\
\hline Bicuda & Boulengerella maculata \\
\hline Pescada branca & Cynoscion leiarchus \\
\hline Pirapema & Megalops atlanticus \\
\hline Tambaqui & Colossoma macropomum \\
\hline
\end{tabular}

Em anos anteriores, o cardápio alimentar de populações tradicionais na Amazônia (em termos de proteína) era constituído principalmente por peixe com farinha, padrão observado em vários estudos (Adams; Murrieta; Sanches, 2005; Murrieta; Dufour,
2004; Murrieta et al., 2008). Entretanto, Silva et al. (2008), ao analisar as causas da insegurança alimentar e nutricional em seis comunidades quilombolas de Santarém/PA, mostra-nos que a disponibilidade de peixes tem sido frequentemente baixa por conta das ameaças ambientais.

Begossi et al. (2019) associaram o declínio dos recursos pesqueiros às seguintes causas: poluição, destruição do habitat, sobrepesca e, principalmente, barragens de rios para projetos hidrelétricos. Tais fatores podem ameaçar a segurança alimentar dos povos tradicionais da Amazônia, visto que as principais espécies de peixe consumidas vêm sendo afetadas pelo impacto das barragens (Arregui, 2015; Begossi et al., 2019).

Outro importante alimento ligado ao hábito de consumo dos quilombolas que se encontra ameaçado é a carne de caça. De acordo com Torres et al. (2018), a fragmentação da Amazônia e a diminuição da cobertura florestal são fatores com efeitos negativos na disponibilidade de espécies de caça. Para os autores, as pessoas de áreas mais remotas e em áreas florestadas estão propensas ao consumo de carne de caça, sendo, assim, mais dependentes dela para a subsistência - o que as torna mais vulneráveis às políticas policiais sobre caça.

Figueiredo e Barros (2016), entretanto, apontam outros fatores limitantes do consumo desse gênero alimentício: para eles, a carne de caça está ligada às representações simbólicas que os animais têm para as comunidades quilombolas. Os autores, ao analisarem o desempenho da caça de animais silvestres como fator para a reprodução física e simbólica de famílias quilombolas de Joana Peres/PA, evidenciaram que carnes das espécies T. terrestris (anta), T. tajacu (caititu), C. paca (paca), E. sexcinctus (tatupeba) e M. americana (veado-mateiro) eram classificadas como reimosas, o que as tornava impróprias para o consumo. Esse debate sobre o modelo de reima na Amazônia, iniciado em 1978, reforça um sistema classificatório de saúde-doença estendido também ao consumo de peixes e frutas, que tem contribuído para a diminuição do leque de possibilidades das escolhas alimentares concomitante à busca pela manutenção dos recursos ambientais.

A participação de frutas e verduras na dieta dos entrevistados foi baixa. A média de consumo ficou 
em torno de 5,8\% para verduras e legumes e de $4,4 \%$ para frutas. Nas refeições, as frutas eram oferecidas na forma de sucos ou consumidas in natura no período da manhã; as verduras e os legumes, como temperos ou em sopas, no período da noite.

Na Amazônia, esses resultados evidenciam o papel secundário desses alimentos na dieta local. Murrieta (2001), ao analisar a dieta ribeirinha na região de Santarém, apontou que temperos, verduras e frutas tinham um consumo ocasional, incluídos na categoria periférica de "não comida" (categoria que faz alusão aos alimentos leves, direcionados às crianças e consumidos esporadicamente). Estudos com populações amazônicas têm demonstrado que a oferta desses alimentos sofre influência de dois fatores: a ecologia local - áreas de várzea e terra firme - e restrições e tabus alimentares - frutas ácidas e não ácidas, chás, entre outros (Adams; Piperata, 2014; Ivanova, 2010; Murrieta, 1998).

Por fim, observou-se ainda a ocorrência de $20 \%$ de produtos industrializados e de fácil preparação, o que chama a atenção pela baixa frequência desses alimentos entre as famílias. Entretanto, apesar do consumo reduzido, estudos como o de Frozi (2014) com quilombolas de todo o país indicaram que $62 \%$ dos entrevistados classificados como extremamente pobres tiveram acesso a tais produtos. Isso demonstra uma forte tendência para o aumento de consumo de ultraprocessados entre os povos e comunidades tradicionais.

Nas comunidades de São João e Santo Antônio, a diversidade alimentar expressou-se ainda no modo de preparação dos alimentos do grupo carne e na substituição do cardápio do jantar - por vezes referido como igual ao almoço. A técnica de preparação da carne restringiu-se à carne assada de panela e à carne guisada com ou sem legumes. 0 frango e o peixe, na maioria das vezes, eram fritos ou assados com limão e sal; já a conserva, o charque e o ovo, oferecidos sempre fritos em óleo.

\section{- Guia Alimentar para a População Brasileira e as comunidades quilombolas}

O GAPB, republicado em novembro de 2014, traz abordagens inovadoras sobre a alimentação e a nutrição na promoção da saúde da população brasileira. Visando reduzir as doenças crônicas não transmissíveis no país, o guia permite entender o processamento industrial dos alimentos e seus efeitos, além de buscar o diálogo com as diferenças culturais e os sistemas alimentares social e ambientalmente sustentáveis.

A transição alimentar (e consequentemente nutricional) motivou uma nova classificação dos alimentos. Por causa da epidemia de obesidade e demais enfermidades, e de sua associação com os alimentos industrializados, a importância dos nutrientes deixou de ser associada à função que eles têm no organismo como energéticos - fontes de carboidratos e gorduras -, construtores - fontes de proteínas - e reguladores - fontes de vitaminas e minerais, passando a enfatizar o modo como os alimentos são processados a partir dos grupos: alimentos in natura ou minimamente processados, óleos, gorduras, sal e açúcar (classificados como ingredientes culinários), alimentos processados e alimentos ultraprocessados (Brasil, 2014).

A conformação dessa perspectiva levou a quatro recomendações e a uma "regra de ouro" no GAPB: faça dos alimentos in natura ou minimamente processados a base da sua alimentação; utilize os ingredientes culinários em pequenas quantidades; limite o uso de alimentos processados; evite produtos ultraprocessados e prefira sempre alimentos in natura ou minimamente processados e preparações culinárias a alimentos ultraprocessados. Estudos como os de Franco et al. (2015) identificaram avanços significativos no perfil nutricional de brasileiros que baseiam sua alimentação em alimentos in natura ou minimamente processados, incluindo uma alta ingestão de frutas, legumes e verduras e o baixo consumo de produtos processados e industrializados.

Quanto aos aspectos socioculturais e simbólicos, o documento destaca: a culinária e a comensalidade, o prazer em comer em companhia, em ambientes apropriados e com atenção, de forma a construir conexões com o hábito do consumo. Andrade e Bocca (2016), em uma análise comparativa de guias alimentares entre países, enfatizaram os benefícios que o GAPB traz para a obtenção de práticas alimentares sadias, tendo como diferencial a ideia de valorização dos aspectos simbólicos, emocionais e ambientais que permeiam o ato de comer - reflexo 
do conceito de segurança alimentar e nutricional vigente no Brasil.

Exemplos como esses reforçam as razões para as escolhas de alimentos saudáveis e levam o GAPB a encorajar sua aplicação a todos os brasileiros. É por esse motivo que o guia deve ser utilizado nos domicílios, nos espaços institucionais (escolas, unidades de saúde, centros de referência de assistência social, entre outros), além de em lugares em que existam representações sociais (centros comunitários, sindicatos, centros de formação de trabalhadores e sedes de movimentos sociais). Da mesma forma, sua comunicação com os diversos povos deve ser estabelecida.

Embora o novo guia considere as dimensões sociais e culturais nas práticas alimentares, não há representações apropriadas ou específicas destinadas aos povos e comunidades tradicionais (Corrêa; Cardoso; Silva, 2020). As decisões sobre o que e como comer de grupos identitários têm como base o cuidado com as memórias coletivas e, em condições amazônicas, com o processo de adaptabilidade às condições sazonais da natureza (Murrieta; Dufour, 2004).

Por se tratar de orientações gerais, o guia acentuou os dilemas em torno do acesso a alimentos em áreas rurais. Para além das injustiças sociais que impactam a autonomia alimentar, como a indisponibilidade de recursos naturais, a não titulação de suas terras, o baixo poder aquisitivo e o racismo, o amplo olhar do documento também promoveu tensões nas comunidades tradicionais da Amazônia.

Com base na realidade das comunidades de Santo Antônio e São João na adoção das recomendações do GAPB, a abrangência das medidas expôs questões difíceis de equacionar quando o assunto era alimentação saudável. No que se refere ao cotidiano da vida das famílias quilombolas, ressaltam-se, entre outras:

1. Incentivar o aumento da ingestão de frutas in natura na dieta local. No que se refere a região Norte do país, as frutas, em sua maioria, por serem ácidas, estimulam a adição de açúcar nas preparações. Segundo a obra Alimentos regionais brasileiros, do Ministério da Saúde, das 30 frutas citadas, $76,67 \%$ orientavam o uso culinário em formas de licores, compotas, geleias, sucos, sorvetes e doces (Brasil, 2015).
2. Promover o consumo do pescado. A adoção da orientação, em caráter geral, afasta as identidades culinárias construídas em torno do "peixe frito". Quando existe a pesca artesanal (antigamente mais presente nas comunidades tradicionais), os peixes do tipo acará, anujá, aracu, piaba, bagre, bicuda, pescada branca, pirapema e tambaqui são preferidos para consumo na forma frita em detrimento dos caldos e cozidos. Barbosa et al. (2007), ao analisar as características comportamentais de consumidores de peixe em Belém/ PA, demonstraram que a preferência da preparação para o consumo do pescado tem relação direta com a espécie do peixe.

3. Limitar o consumo de alimentos processados e ultraprocessados. Um dos principais desafios da implantação do guia nos quilombos está em, simultaneamente, reduzir a quantidade de tais alimentos da mesa dos domicílios e também dos espaços coletivos e instrucionais. Nascimento e Guerra (2016) mostraram como o consumo de alimentos se modificou, com a maior inclusão de produtos industrializados e de fácil preparação. Seja no mercado, nas feiras ou mesmo nas escolas e reuniões coletivas, os alimentos como macarrão instantâneo, enlatados e embutidos, sucos industrializados e refrigerantes, tiveram elevada presença.

As comunidades quilombolas têm sua identidade ligada à ideia de pertencimento. É uma identidade coletiva, cujos laços são construídos com base em valores, costumes e lutas comuns, para além dos elementos estruturais que tornam cada grupo diferente dos demais; por essa razão, orientações relacionadas à alimentação devem levar em conta tais questões.

Considerando o exposto e reconhecendo que o GAPB é uma importante referência entre os guias alimentares atuais no mundo - Estados Unidos, Canadá, Reino Unido, Chile, Nova Zelândia e Suécia -, é importante examinar contextos complexos como forma de incentivar diretrizes que valorizem a autonomia nas escolhas alimentares da população. 
Embora o novo guia resgate os valores simbólicos do alimento, observa-se que não há representações apropriadas e específicas para povos e comunidades tradicionais. A estratégia das populações quilombolas baseada na combinação de alimentos mostra um cenário de limitada adesão às orientações oficiais sobre alimentação saudável no país.

\section{Considerações finais}

A Amazônia é reconhecida pela sua vasta biodiversidade. $\mathrm{O}$ acesso aos alimentos da floresta, no entanto, depende de condições sazonais, socioeconômicas e culturais - é nesse contexto que estão inseridas as comunidades quilombolas de Santo Antônio e São João.

Nessas comunidades, o café adoçado, o trinômio arroz-feijão-farinha e a carne vermelha - incluindo animais silvestres - foram os alimentos mais referidos pelos participantes, configurando refeições com alto índice de tubérculos e cereais e baixa oferta de frutas e verduras. Nesse sentido, a aplicação das orientações do GAPB a grupos quilombolas enfrenta desafios socioculturais, econômicos e ambientais para a construção de hábitos alimentares adequados e saudáveis, uma vez que estas não são consideradas na formulação do guia.

Reconhecemos que o GAPB adaptou a linguagem sobre as condições nutricionais de forma que a mensagem pudesse ser entendida por todos, renunciando aos valores numéricos das quantidades de nutrientes. As representações sobre hábitos saudáveis, entretanto, ainda necessitam de adaptações às realidades dos povos e comunidades tradicionais. Guias alimentares são importantes para o alcance da saúde e nutrição da população, mas precisam ser combinados a outras intervenções que respeitem a diversidade cultural do país.

Neste estudo não se teve a pretensão de contemplar todas as possibilidades contidas no guia em razão das limitações de informações obtidas em campo. Buscou-se, contudo, refletir sobre sua utilidade como instrumento analítico em relação às questões vivenciadas pelas comunidades quilombolas e contribuir com orientações consistentes sobre "padrões alimentares" que promovam o bem-estar dos grupos étnicos-raciais brasileiros.

\section{Referências}

ADAMS, C.; MURRIETA, R. S. S.; SANCHES, R.

A. Agricultura e alimentação em populações ribeirinhas das várzeas do Amazonas: novas perspectivas. Ambiente \& Sociedade, Campinas, v. 8, n. 1, p. 1-23, 2005.

ADAMS, C.; PIPERATA, B. Ecologia humana, saúde e nutrição na Amazônia. In: VIEIRA, I. C. G.; TOLEDO, P. M.; SANTOS JÚNIOR, R. A. O. Ambiente e sociedade na Amazônia: uma abordagem interdisciplinar. Rio de Janeiro: Garamond, 2014. p. 341-378.

ALMEIDA, S. S. et al. Indicadores socioeconômicos, sociodemográficos, saúde e nutricionais da comunidade remanescente quilombola Mangueiras. In: RAMOS, E. M. L. S. et al. (Org.). Métodos e ações nutricionais em quilombos. Belém: UFPA, 2016. p. 8o-110.

ANDRADE, L. M.; BOCCA, C. Análise comparativa de guias alimentares: proximidades e distinções entre três países. Demetra, Rio de Janeiro, v. 11, n. 4, p. 1001-1016, 2016.

ARAÚJO, R. L. M. S. et al. Condições de vida, saúde e morbidade referida de comunidades quilombolas do semiárido baiano, Brasil. Revista Baiana de Saúde Pública, Salvador, v. 43, n. 1, p. 226-246, 2019. DOI: 10.22278/2318-266o.2019.v43.n1.a2988

ARREGUI, A. Amazonian quilombolas and the technopolitics of aluminum. Journal of Material Culture, Thousand Oaks, v. 20, n. 3, p. 249-272, 2015.

BARBOSA, J. A. et al. Características comportamentais do consumidor de peixe no mercado de Belém. Boletim Técnico-Científico do CEPNOR, Belém, v. 7, n. 1, p. 115-133, 2007.

BEGOSSI, A. et al. Fish consumption on the Amazon: a review of biodiversity, hydropower and food security issues. Brazilian Journal of Biology, São Carlos, v. 79, n. 2, p. 345-357, 2019.

BOATEMAA, S.; DRIMIE, S.; PEREIRA, L.

Addressing food and nutrition security in South Africa: a review of policy responses since 2002. African Journal of Agricultural and Resource Economics, Seattle, v. 13, n. 3, p. 264-279, 2018. 
BORGES, W. D. Prevalência da hipertensão arterial sistêmica e seus determinantes bioantropológicos em populações quilombolas da Amazônia. 2011. Dissertação (Mestrado em Saúde, Sociedade e Endemias na Amazônia) Universidade Federal do Amazonas, Manaus, 2011.

BRANDÃO, A.; JORGE, A. L. Comunidades quilombolas, acesso a programas sociais e segurança alimentar e nutricional. In: ROCHA, C.; BURLANDY, L.; MAGALHÃES, R. Segurança alimentar e nutricional: perspectivas, aprendizados e desafios para as políticas públicas. Rio de Janeiro: Fiocruz, 2013. p. 213-225.

BRASIL. Decreto $\mathrm{n}^{\circ} 4.887$, de 20 de novembro de 2003. Regulamenta o procedimento para identificação, reconhecimento, delimitação, demarcação e titulação de terras ocupadas por remanescentes das comunidades dos quilombos de que trata o art. 68 do Ato das Disposições Constitucionais Transitórias. Diário Oficial da União, Brasília, DF, 21 nov. 2003. Disponível em: <https://bit.ly/3bQoDbX>. Acesso em: 5 jan. 2021.

BRASIL. Ministério da Saúde. Guia alimentar para a população brasileira. 2. ed. Brasília, DF, 2014. Disponível em: <https://bit.ly/3iptKnO>. Acesso em: 6 jan. 2021.

BRASIL. Ministério da Saúde. Alimentos regionais brasileiros. 2. ed. Brasília, DF, 2015. Disponível em: <https://bit.ly/3oRvkRP>. Acesso em: 6 jan. 2021.

CASCUDO, L. C. História da alimentação no Brasil. 4. ed. São Paulo: Global, 2011.

CAVALCANTE, I. M. S.; SILVA, H. P. Políticas públicas e acesso aos serviços de saúde em quilombos na Amazônia paraense. In: FONTES, A. et al. (Org.). Quilombolas: aspectos políticos, jurídicos e políticas públicas inclusivas consequentes à edição do Decreto ${ }^{\circ} 4.887 / 2003$ e do julgamento da $\operatorname{ADI~}{ }^{0}$ 3.239. Rio de Janeiro: TRF2, 2019. p. 473-498.

CORRÊA, N. A. F.; CARDOSO, L. F. C.; SILVA, H. P. Comida de quilombo na merenda escolar: interfaces entre a cultura alimentar e o Programa Nacional de Alimentação Escolar. Amazônica: Revista de Antropologia, Belém, v. 12, n. 1, p. 145-163, 2020.
FIGUEIREDO, R. A. A.; BARROS, F. B. Caçar, preparar e comer o 'bicho do mato': práticas alimentares entre os quilombolas na Reserva Extrativista Ipaú-Anilzinho (Pará). Boletim do Museu Paraense Emílio Goeldi, Belém, v. 11, n. 3 , p. 691-713, 2016.

FRANCO, E. P. et al. Assessment of the Quality of Hypoenergetic Diet in Overweight Women. International Journal of Cardiovascular Sciences, Rio de Janeiro, v. 28, n. 3, p. 244-250, 2015.

FROZI, D. S. Multidimensionalidade da pobreza em comunidades quilombolas: aspectos analíticos para a segurança alimentar e nutricional. In: PINTO, A. R. et al. Quilombos do Brasil: segurança alimentar e nutricional em territórios titulados. Brasília, DF: Ministério do Desenvolvimento Social e Combate à Fome, 2014. p. 69-91.

GOMES, D. L.; SCHMITZ, H.; BRINGEL, F. O. Identidade e mobilização quilombola na Amazônia marajoara. Boletim Goiano de Geografia, Goiânia, v. 38, n. 3, p. 591-618, 2018.

GOMES, F. S. Mocambos e quilombos: uma história do campesinato negro no Brasil. 4. ed. São Paulo: Claro Enigma, 2015.

GUIMARÃES, R. C. R.; SILVA, H. P. Estado nutricional e crescimento de crianças quilombolas de diferentes comunidades do estado do Pará. Amazônica: Revista de Antropologia, Belém, v. 7, n. 1, p. 186-209, 2015.

IBGE - INSTITUTO BRASILEIRO DE GEOGRAFIA E ESTATÍSTICA. Pesquisa nacional por amostra de domicílios: segurança alimentar 2004/2009. Rio de Janeiro, 2010.

IVANOVA, S. A. Dietary change in ribeirinha women: evidence of a nutrition transition in the Brazilian Amazon? 2010. Tese (Mestrado em Artes e Antropologia) - The Ohio State University, Columbus, 2010.

Melo, M. F. T.; Silva, H. P. Doenças crônicas e os determinantes sociais da saúde em comunidades quilombolas do Pará, Amazônia, Brasil. Revista da ABPN, Goiânia, v. 7, n. 16, p. 168-189, 2015. Disponível em: <https://bit.ly/2LXjE1P>. Acesso em: 26 jan. 2021. 
MURRIETA, R. S. S. O dilema do papa-chibé: consumo alimentar, nutrição e práticas de intervenção na Ilha de Ituqui, baixo Amazonas, Pará. Revista de Antropologia, São Paulo, v. 41, n. 1, p. 97-150, 1998.

MURRIETA, R. S. S. Dialética do sabor: alimentação, ecologia e vida cotidiana em comunidades ribeirinhas da Ilha de Ituqui, baixo Amazonas, Pará. Revista de Antropologia, São Paulo, v. 44, n. 2, p. 39-88, 2001.

MURRIETA, R. S. S.; DUFOUR, D. L. Fish and farinha: protein and energy consumption in Amazonian rural communities on Ituqui Island, Brazil. Ecology of Food and Nutrition, Abingdon, v. 43, n. 3, p. 231-255, 2004.

MURRIETA, R. S. S. et al. Consumo alimentar e ecologia de populações ribeirinhas em dois ecossistemas. Revista de Nutrição, Campinas, v. 21, p. 123s-133s, 2008. Suplemento.

NASCIMENTO, E. C.; GUERRA, G. A. D. Do avortado ao comprado: práticas alimentares e a segurança alimentar da comunidade quilombola do baixo Acaraqui, Abaetetuba, Pará. Boletim do Museu Paraense Emílio Goeldi, Belém, v. 11, n. 1, p. 225-241, 2016.

PINTO, A. R. et al. Quilombos do Brasil: segurança alimentar e nutricional em territórios titulados. Brasília, DF: Ministério do Desenvolvimento Social e Combate à Fome, 2014.

SILVA, A. L.; BEGOSSI, A. Biodiversity, food consumption and ecological niche dimension: a study case of the riverine populations from the Rio Negro, Amazonia, Brazil. Environment, Development and Sustainability, New York, v. 11, n. 3, p. 489-507, 2009.

SILVA, D. O. et al. A rede de causalidade da insegurança alimentar e nutricional de comunidades quilombolas com a construção da rodovia BR-163, Pará, Brasil. Revista de Nutrição, Campinas, v. 21, p. 83s-87s, 2008. Suplemento.

SILVA, H. P. Socio-ecology of health and disease: the effects of invisibility on the caboclo populations of the Amazon. In: ADAMS, C. et al. (Org.). Amazon peasant societies in a changing environment: political ecology, invisibility and modernity in the rain forest. New York: Springer, 2009. p. 307-333.

SILVA, H. P. Life is hard, life is beautiful: some perspectives on Amazonian rural population's health and aging. In: PINEDO-VASQUEZ, M. et al. (Ed.). The Amazonian varzea: the decade past and the decade ahead. New York: Springer, 2011. p. 11-36.

SILVA, H. P.; FILGUEIRAS, L. A. Biological anthropology of children's growth in Amazonia. In: UBELAKER, D.; COLANTONIO, S. E. (Ed.). Biological anthropology of Latin America: historical development and recent advances. Washington, DC: Smithsonian Institution Scholarly Press, 2019. p. 41-58. (Smithsonian Contributions to Anthropology, 51).

SILVA, R. J.; GARAVELLO, M. E. P. E. Ensaio sobre transição alimentar e desenvolvimento em populações caboclas da Amazônia. Segurança Alimentar e Nutricional, Campinas, v. 19, n. 1, p. 1-7, 2012.

TORRES, P. C. et al. Landscape correlates of bushmeat consumption and hunting in a postfrontier Amazonian region. Environmental Conservation, Cambridge, v. 45, n. 4, p. 315-323, 2018.

WHO - WORLD HEALTH ORGANIZATION. Work programme of the United Nations Decade of Action on Nutrition (2016-2025). World Health Organization, Geneva, 27 jan. 2017. Disponível em: <https://bit.ly/3ipdIue>. Acesso em: 6 jan. 2021.

WHO - WORLD HEALTH ORGANIZATION; FAO FOOD AND AGRICULTURE ORGANIZATION OF THE UNITED NATIONS. Second International Conference on Nutrition: Rome Declaration on Nutrition. Rome, 21 nov. 2014. Disponível em: <https://bit.ly/2KuaIjJ>. Acesso em: 6 jan. 2021.

\section{Contribuição dos autores}

Corrêa analisou e interpretou os dados e redigiu o manuscrito. Silva realizou a revisão crítica. Ambos os autores conceberam $e$ delinearam a pesquisa e aprovaram a versão final do documento.

Recebido: $25 / 08 / 2020$

Aprovado: 09/09/2020 